\title{
Complicações da associação das Síndromes do Intestino Irritável e Pós- colecistectomia: um relato de caso
}

Complications of the association of Irritable and Post-cholecystectomy gut Syndromes: a case report

Complicaciones de la asociación de Síndromes del Intestino Irritables y Post-colectistomía: informe de un caso

Recebido: 19/12/2020 | Revisado: 24/12/2020 | Aceito: 06/01/2021 | Publicado: 07/01/2021

\author{
Amanda Sampaio Carrias \\ ORCID: https://orcid.org/0000-0002-2735-2706 \\ Instituto de Educação Superior do Vale do Parnaíba, Brasil \\ E-mail: amanda_carrias@hotmail.com \\ Ana Gabriela Freitas Borges \\ ORCID: https://orcid.org/0000-0001-6045-5304 \\ Instituto de Educação Superior do Vale do Parnaíba, Brasil \\ E-mail: gabryella_freitasborges@hotmail.com \\ Luan Kelves Miranda de Souza \\ ORCID: https://orcid.org/0000-0002-8019-4022 \\ Instituto de Educação Superior do Vale do Parnaíba, Brasil \\ E-mail: luankelves11@gmail.com
}

\begin{abstract}
Resumo
Objetivo: Descrever os principais achados clínicos da síndrome pós-colecistectomia e da síndrome do intestino irritável. Relato de Caso: A síndrome pós-colecistectomia (SPC) é o termo utilizado para descrever a persistência de cólica biliar ou dor abdominal no quadrante superior direito com uma variedade de sintomas gastrointestinais, semelhantes às características experimentadas por um indivíduo antes da colecistectomia. Esses sintomas compreendem intolerância a alimentos gordurosos, náusea, vômito, azia, flatulência, indigestão, diarreia, icterícia e episódios intermitentes de dor abdominal. A SPC pode apresentar-se no pós-operatório, como também pode se manifestar meses a anos após a cirurgia. A síndrome do intestino irritável (SII) é um distúrbio funcional crônico do trato gastrointestinal caracterizado por dor abdominal recorrente e hábitos intestinais alterados, pelo menos um dia na semana por três meses com dois ou mais dos seguintes itens: defecação, associados a uma alteração na frequência de fezes ou associado a uma alteração na forma (aparência) das fezes, na ausência de uma patologia orgânica. Sabe-se ainda que a associação das duas síndromes seja um evento raro, devendo ser investigado causas biliares, extra biliares e psicogênicas. Considerações Finais: Este relato de caso tem por propósito agregar informações sobre as duas síndromes.
\end{abstract}

Palavras-chave: Síndrome pós-colecistectomia; Síndrome do intestino irritável; Trato gastrointestinal.

\begin{abstract}
Objective: Describe the main clinical findings of post-cholecystectomy syndrome and irritable bowel syndrome. Case Report: Post-cholecystectomy syndrome (SPC) is the term used to describe the persistence of biliary colic or abdominal pain in the upper right quadrant with a variety of gastrointestinal symptoms, similar to the characteristics experienced by an individual before cholecystectomy. These symptoms include intolerance to fatty foods, nausea, vomiting, heartburn, flatulence, indigestion, diarrhea, jaundice and intermittent episodes of abdominal pain. SPC can present itself in the postoperative period, as well as it can manifest months to years after the surgery. Irritable bowel syndrome (IBS) is a chronic functional disorder of the gastrointestinal tract characterized by recurrent abdominal pain and altered bowel habits, at least one day a week for three months with two or more of the following items: defecation, associated with a change in frequency of stools or associated with a change in the shape (appearance) of the stools, in the absence of an organic pathology. It is also known that the association of the two syndromes is a rare event, and biliary, extra-biliary and psychogenic causes should be investigated. Final Considerations: The purpose of this case report is to add information about the two syndromes.
\end{abstract}

Keywords: Post-cholecystectomy syndrome; Irritable bowel syndrome; Gastrointestinal tract.

\section{Resumen}

Objetivo: Describir los principales hallazgos clínicos del síndrome poscolecistectomía y el síndrome del intestino irritable. Reporte de un caso: Síndrome post-colecistectomía (SPC) es el término utilizado para describir la persistencia del cólico biliar o el dolor abdominal en el cuadrante superior derecho con una variedad de síntomas 
gastrointestinales, similares a las características experimentadas por un individuo antes de la colecistectomía. Estos síntomas incluyen intolerancia a los alimentos grasos, náuseas, vómitos, acidez estomacal, flatulencia, indigestión, diarrea, ictericia y episodios intermitentes de dolor abdominal. El SPC puede presentarse en el postoperatorio, así como también puede manifestarse meses o años después de la cirugía. El síndrome del intestino irritable (SII) es un trastorno funcional crónico del tracto gastrointestinal caracterizado por dolor abdominal recurrente y hábitos intestinales alterados, al menos un día a la semana durante tres meses con dos o más de los siguientes elementos: defecación, asociada con un cambio en frecuencia de las heces o asociado con un cambio en la forma (apariencia) de las heces, en ausencia de una patología orgánica. También se sabe que la asociación de los dos síndromes es un evento raro, y se deben investigar las causas biliares, extrabiliares y psicógenas. Consideraciones finales: El propósito de este informe de caso es agregar información sobre los dos síndromes.

Palabras clave: Síndrome post-colecistectomía; Síndrome del intestino irritable; Tracto gastrointestinal.

\section{Introdução}

Desde a implantação em 1986, a colecistectomia laparoscópica (CL) tem sido considerada o tratamento de escolha para várias patologias da vesícula biliar. Entretanto, ao longo do tempo observou-se que alguns pacientes apresentavam um conjunto de sinais e sintomas semelhantes aos experimentados antes da colecistectomia (Hongbeom Kim, et al., 2018). A incidência varia amplamente, de acordo com estudos clínicos, sendo entre 5-15\%, 5-30\% e 15-47\%. O início dos sintomas pode variar de 2 dias a 25 anos, a prevalência relacionada ao gênero é maior em pacientes do sexo feminino em comparação aos pacientes do sexo masculino (Shirah, et al., 2018).

Esse conjunto de sinais e sintomas foi denominado de Síndrome Pós Colecistectomia (SPC), dentre esses estão, dor em quadrante superior direito, náuseas, vômitos, flatulência, dispepsia, cólica abdominal, febre e em alguns casos, icterícia. No entanto, os estudos relacionados à síndrome são recentes e não há dados suficientes para determinar a etiologia e prevenção da doença de forma específica (Jaunoo, 2010). Esse conjunto de sinais e sintomas foi denominado de Síndrome Pós Colecistectomia (SPC), dentre esses estão, dor em quadrante superior direito, náuseas, vômitos, flatulência, dispepsia, cólica abdominal, febre e em alguns casos, icterícia. No entanto, os estudos relacionados à síndrome são recentes e não há dados suficientes para determinar a etiologia e prevenção da doença de forma específica (Jaunoo, 2010).

Os motivos mais comuns da síndrome pós-colecistectomia, compreendem os sintomas de origem biliar, que incluem diarreia ou gastrite induzida por sal biliar, abscesso, biloma crônico, cálculos retidos, vazamento de bile, estenoses biliares, remanescente de ducto cístico longo, estenose e discinesia do esfíncter de Oddi; Há também outras causas de sintomas de origem extrabiliar, como esofagite de refluxo, úlcera péptica, doença do refluxo gastresofágico, pancreatite aguda ou crônica, tumores pancreáticos, pâncreas divisum, hepatite, doenças esofágicas, isquemia mesentérica, diverticulite, distúrbios intestinais orgânicos ou motores e síndrome do intestino irritável (SII) (Shirah, et al., 2018).

Em consequência da excreção aumentada dos sais biliares há uma resposta inflamatória crônica do cólon, por conseguinte ocorre a modificação da motilidade gastrointestinal tornando evidente associação da SPC com a síndrome do intestino irritável, que é um distúrbio funcional do trato digestivo, expressado através da acentuação, inibição ou modificação da função intestinal, associado à alteração do habito intestinal com constipação, diarreia ou as duas, além de muco nas fezes, urgência retal, distensão abdominal e flatulência (Madacsy, et al., 2015).

São incluídas conjuntamente causas extra intestinais, como doença arterial coronariana, síndromes de dor inexplicáveis e distúrbios psiquiátricos e neurológicos. Sabe-se ainda que variáveis psicológicas tenham fundamental importância no início de sintomas subjetivos e devem ser investigadas individualmente (Shirah, et al., 2018).

Alguns estudos relatam tratamento medicamentoso para a SII, ainda que paliativo, com antidiarreicos (Loperamida), agentes serotoninérgicos (Alosetron), opiáceos, antiespasmódicos (Otilônio e Hioscina), agentes laxativos, agentes prosecretores (Lubiprostona- não disponível no Brasil), probióticos, antidepressivos - tricíclicos e inibidores seletivos da receptação de serotonina, além de terapia não medicamentosa, que inclui dieta, suplementação de fibra, exercícios físicos e terapias psicológicas (Chey, et al., 2015). 
Mediante isso, a realização do presente estudo se justifica pela escassez de estudos publicados com achados clínicos e fisiopatológicos entre a associação da SPC e SII. Dessa forma, este relato de caso tem por propósito agregar informações sobre as duas síndromes.

\section{Metodologia}

O presente trabalho, trata-se de um relato de caso, que consiste em uma descrição detalhada de um caso clinico contento aspectos importantes sobre sinais, sintomas e outras características do paciente, relatando os procedimentos terapêuticos utilizados como também o desenrolar do caso. As informações que contidas neste estudo foram adquiridas através de entrevista e questionários realizados com o paciente (mediante assinatura do Termo de Consentimento Livre e Esclarecido TCLE) e análise de base de dados PubMed e Medline, de artigos de ensaio clínico realizados entre 2000 e 2018. Para isso, foram utilizados os seguintes descritores "síndrome pós-colecistectomia", "síndrome do intestino irritável” em português, “postcholecystectomy syndrome”, “irritable bowel syndrome”, em inglês. Foram selecionados artigos (critérios de inclusão) que analisaram perfis sintomatológicos de pacientes pós colecistectomia laparoscópica buscando correlacionar à síndrome póscolecistectomia como agravante da síndrome do intestino irritável e aqueles que não apresentavam os temas abordados foram excluídos da pesquisa (critérios de exclusão).

Além disso, o presente estudo foi devidamente aprovado pelo o Comitê de Ética em Pesquisa do Centro Universitário Tocantinense Presidente Antônio Carlos - UNITPAC, com o número de parecer 4.085.744, do ano de 2020.

\section{Relato de Caso}

Paciente J.B.B., sexo masculino, 60 anos, há sete anos foi submetido à cirurgia de colecistectomia, em que foi retirado micro cálculos, na ocasião não apresentava nenhum sinal ou sintoma. Após dois anos da cirurgia, notou um desequilíbrio da função intestinal apresentando diarreia frequente, dor em quadrante superior direito, flatulência e cólica abdominal. Concomitante aos sintomas apresentados foi realizada uma colonoscopia, na qual foram encontrados e retirados pólipos intestinais e após análise anatomo patológico verificou-se que eram adenomas túbulo-vilosos, presença de atipia citoarquitetural: intensa e forma macroscópica: pediculada (Figura 1A e 1B).

Figura 1: Na Figura 1A nota-se a presença de um pólipo laçado, enquanto na figura 1B consta a presença de um pólipo subpediculado. Fonte: Ambas as imagens foram obtidas através de um exame de colonoscopia.
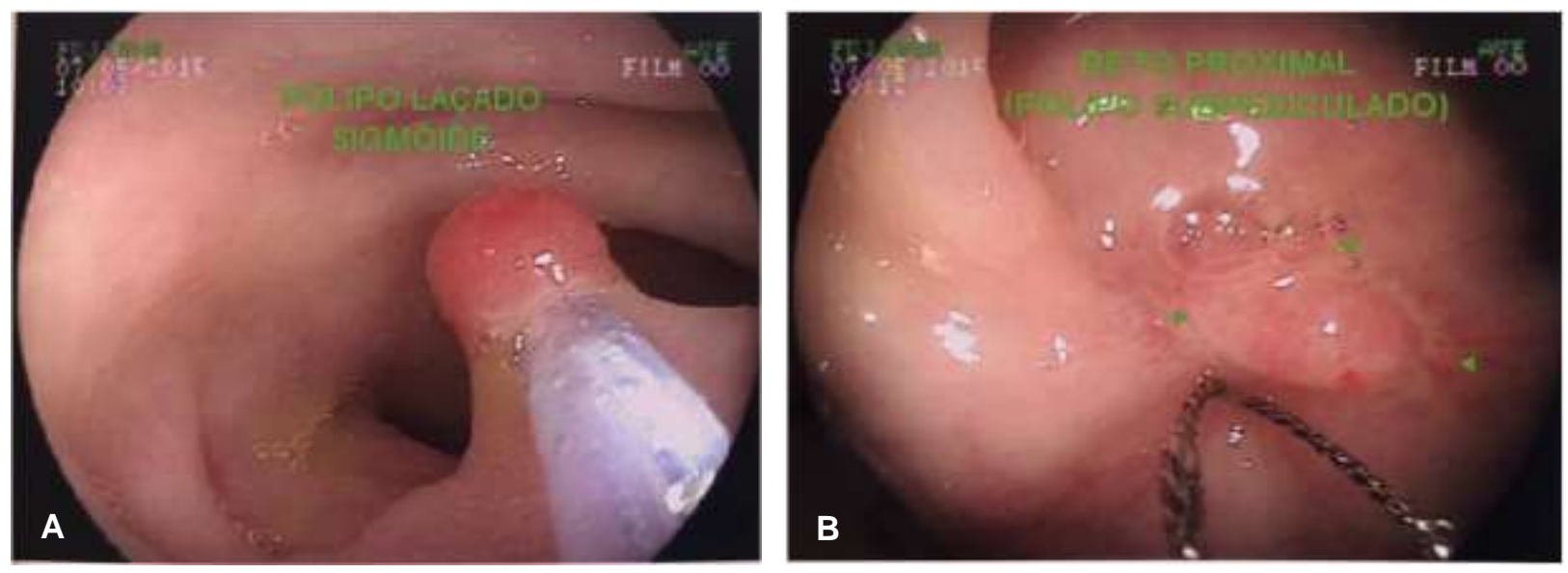

Fonte: Exames cedidos pelo paciente em estudo. 
Dois anos após foi realizado uma endoscopia digestiva alta que evidenciou gastrite enantemático edematosa moderada de corpo e xantomas de incisura, e teste positivo para H.pylori (Figura 2). No mesmo período foi realiza uma ultrassonografia de abdome superior, mostrando apenas um cisto em lobo hepático direito (Figura 3) não apresentando nenhuma repercussão clínica. Diante desse quadro o médico prescreveu colestiramina (Questran ${ }^{\circledR}$ ). Fez uso por 3 anos, com pouca melhora do quadro. Pela pouca resposta ao tratamento e os sinais clínicos do paciente compatíveis com a síndrome do intestino irritável, o gastroenterologista indicou tratamento com psiquiatra. No qual foi receitado duas medicações, eszopiclona (Prysmaß) e succinato de desvenlafaxina monoidratado (Imense $\left.{ }^{\circledR}\right)$. Em uso atual e com melhora significativa do quadro.

Figura 2: Está ilustrado na Figura 2A o esôfago distal; 2B duodeno; 2C estômago; 2D bulbo duodenal; 2E fundo gástrico; 2F Corpo gástrico. Na qual se evidenciou gastrite enantemático edematosa moderada de corpo e xantomas de incisura, e teste positivo para H.pylori. Imagens foram obtidas através de um exame de endoscópico digestivo alto (exame cedido pelo paciente em estudo).
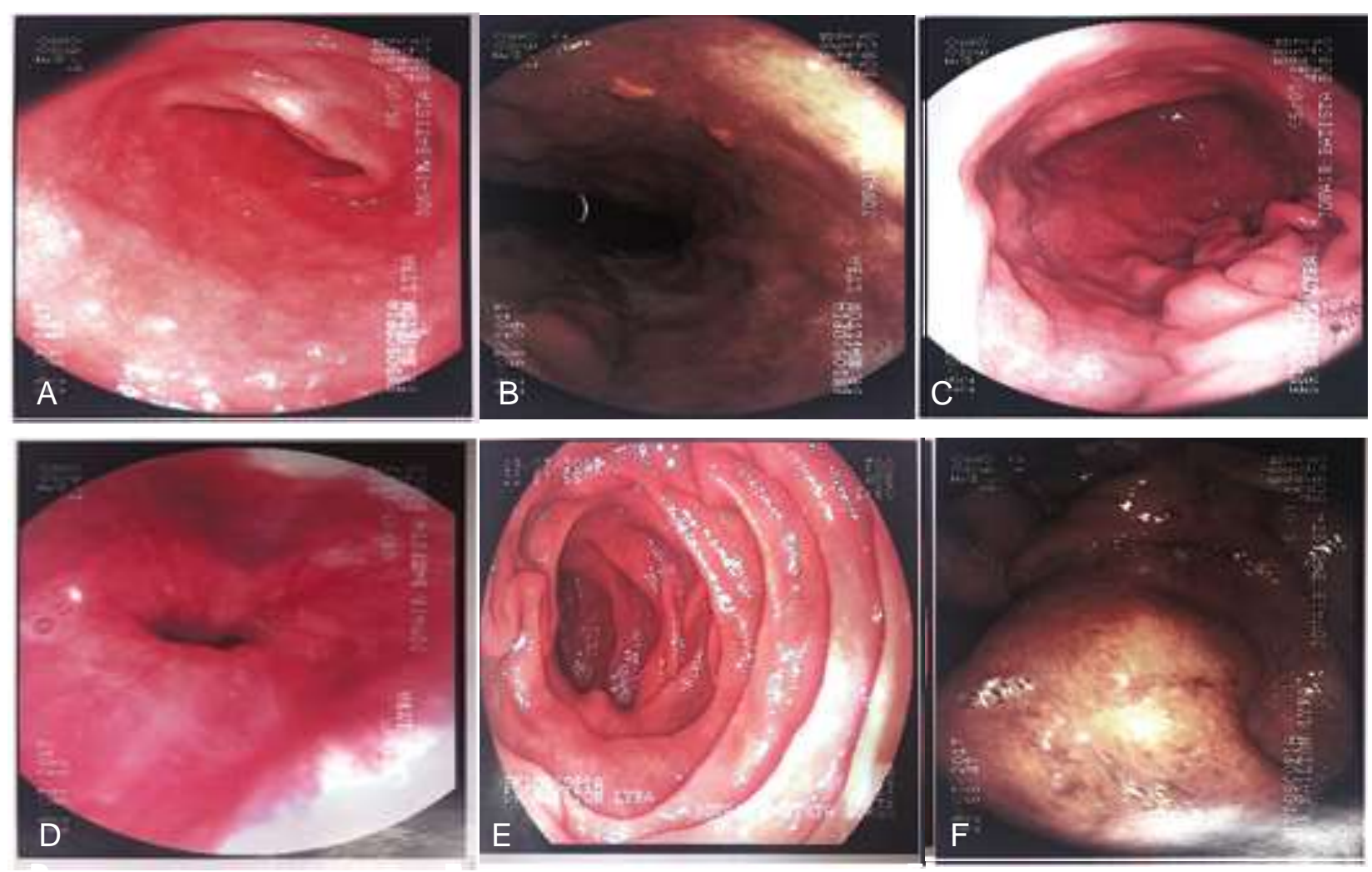

Fonte: Exames cedidos pelo paciente em estudo. 
Figura 3: Está ilustrado na Figura 3A o pâncreas; 3B e 3C Fígado; 3D Veia Porta/ Topog. Vesícula biliar; 3E Rim E/D; 3F Baço. Em que se destaca um cisto no lobo hepático direito. Imagens obtidas através de exame ultrassonográfico de abdome superior (exame cedido pelo paciente em estudo).

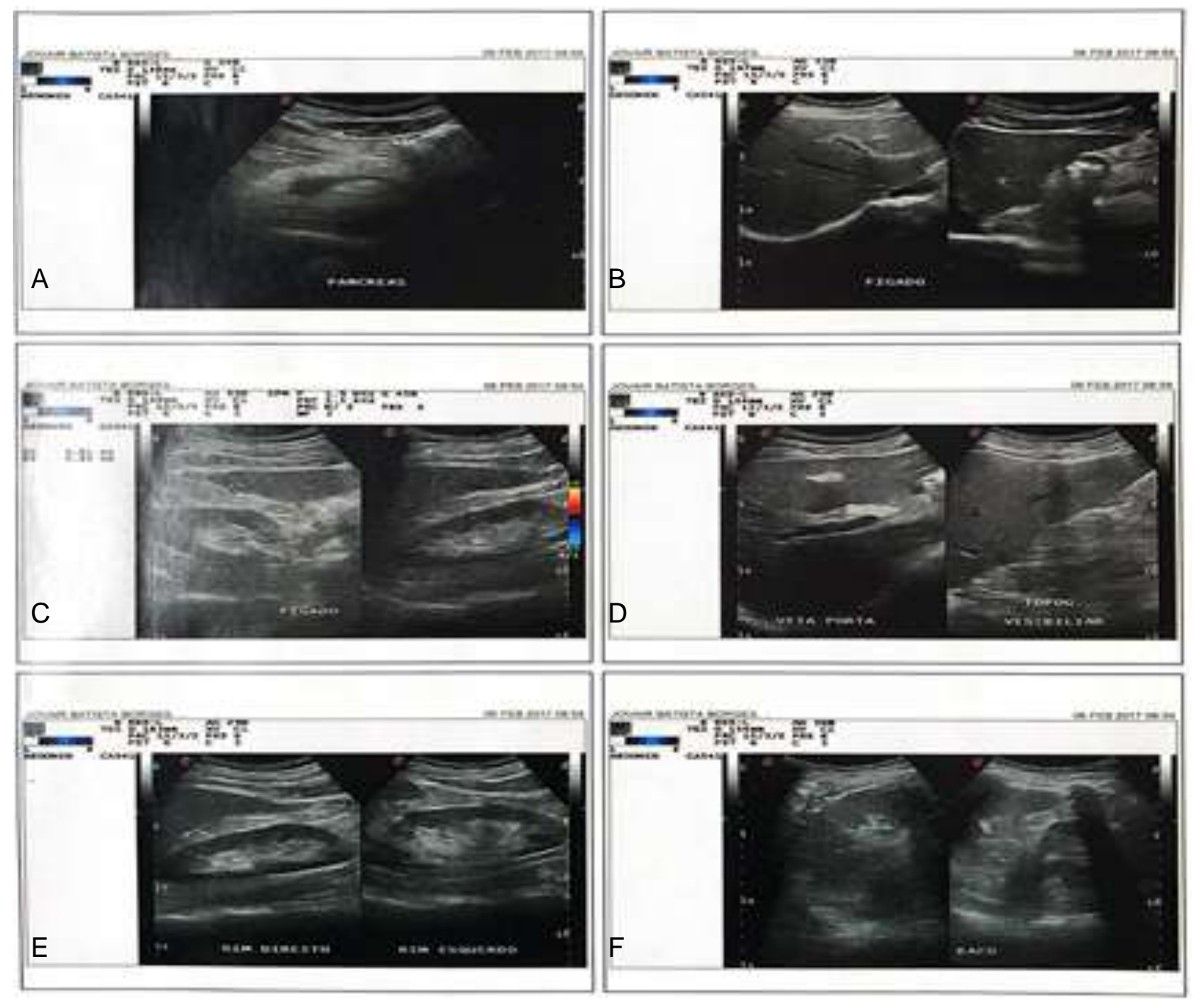

Fonte: Exames cedidos pelo paciente em estudo.

\section{Discussão}

Diante do caso explicitado observou-se que os achados clínicos das Síndromes Pós- Colecistectomia (SPC) e Intestino Irritável (SII) são fundamentais para o diagnóstico, já que é dado por exclusão após realização de exames complementares, como Ultrassonografia (USG) que possui alta sensibilidade para detectar cálculos e espessamento da parede, pode-se visualizar também liquido perivesicular, distensão e cálculos impactados; Endoscopia Digestiva Alta (EDA), utilizada para examinar o esôfago, o estômago e o duodeno através da introdução por via oral de um aparelho endoscópico; a Colonoscopia, utilizada para examinar o revestimento interno do intestino grosso, através de um aparelho endoscópico. Esses exames são usados para descartar outras patologias do trato gastrointestinal.

De acordo com as imagens apresentadas, na EDA o paciente apresentou gastrite, uma das complicações extrabiliares mais frequentes observadas na SPC. Outro achado de suma importância para o acompanhamento do caso, é a presença de pólipos, que no período anterior à realização do exame (colonoscopia) o paciente notou a presença de hematoquezia e pode 
indicar causas como hemorroidas, fissura anal e pólipos, esses são adenomas geralmente assintomáticos e frequentemente achados pelos testes de rastreamento de câncer de cólon.

Estuda-se a SPC como um diagnóstico indeterminado, iniciando uma investigação adequada de cada caso. Denominase SPC, as modificações diretamente relacionadas com as vias biliares, resultantes de complicações da colecistectomia, de um tratamento cirúrgico incompleto, falha do diagnóstico e correção de alguma complicação da doença litiásica preexistente, que possivelmente tenha passado despercebida durante a cirurgia. Dentre os quais estão à estenose pós-cirúrgica dos canais biliares, a litíase ductal residual, a vesícula residual e a síndrome de ducto cístico remanescente, a estenose do Oddi e a discinesia biliar/disfunção do esfíncter de Oddi (Dani; Passos, 2011).

A SII é caracterizada por sintomas, inespecíficos, em sua maioria são indicativos de alterações emocionais. A principal manifestação sintomática é a dor abdominal, geralmente em cólica, sem ritmo, variando de intensidade de acordo com o estado emocional do paciente, quase sempre acompanhada de distúrbios do ritmo intestinal, alternando diarreia com períodos de obstipação (Porto, 2014). O diagnóstico da SII tem como referência a presença dos sinais e sintomas característicos além de usar os critérios de Roma III (classificação de desordens gastrointestinais funcionais) que consiste em avaliar: dor ou desconforto abdominal recorrente, associada a dois ou mais sintomas como, a melhora com a defecação; início associado com mudança na frequência das evacuações; início associado com mudança no formato (aparência) das fezes (Drossman, et al., 2006).

O paciente do caso foi submetido a uma entrevista, na qual foi questionado sobre início e frequência dos sintomas, mudança dos hábitos de vida, mudanças após a colecistectomia. Além de ser avaliado pelos critérios de Roma III. Após a análise de dados, o paciente se enquadra na sintomatologia apresentada, a partir disso, foi prescrito tratamento com colestiramina (Questran®), usado para auxiliar no tratamento de reidratação no quadro diarreico devido à má absorção de ácidos biliares resultante de distúrbios funcionais (orgânicos ou cirúrgicos), fez uso durante três anos, sem obtenção de melhora significativa.

Depois da avaliação do quadro, foi indicado consulta com médico psiquiatra o qual indicou o uso de eszopiclona (Prysma®) e succinato de desvenlafaxina monoidratado (Imense®), facilitam a inibição mediada por ácido gamaaminobutírico (GABA), através da ligação a uma subunidade do complexo receptor GABA chamado receptor benzodiazepínico. O complexo receptor GABA está presente em todo o cérebro, incluindo a área pré-óptica lateral ventral que controla o sono. (Roehrs; Roth, 2019); Inibidores seletivos da recaptação de serotonina e noradrenalina (ISRSN) tratam a depressão, bloqueando inicialmente as proteínas transportadoras pré-sinápticas da serotonina e da noradrenalina (Nelson, 2020), respectivamente, com melhora significativa do quadro.

Além da terapia farmacológica, foi instruido ao paciente modificação do estilo de vida, como inclusão de alimentos ricos em fibra (ameixa, mamão, melão, laranja, etc); diminuição da ingestão de alimentos gordurosos, produtores de gás (feijão, repolho, cebola etc) e lactose (leite e derivados), prática de exercícios físicos e terapia psicológica.

Visto que os achados clínicos sobre as complicações da SPC associada à SII possuem poucos estudos, nota-se que é necessário que seja esclarecido ao paciente sobre os riscos/benefícios quando submetido à Colecistectomia apesar da incidência ser relativamente pequena, as síndromes afetam a qualidade de vida. Sugere-se que seja feito um questionário para os pacientes que apresentam quadro clínico semelhante, já que não há exames de imagem/laboratoriais que oferecem um diagnóstico preciso.

\section{Referências}

Adilson, P., et al. Entendendo as razões para recusa da colecistectomia em indivíduos com colelitíase: Como ajuda-los em sua decisão? Arq Bra Cir Dig, 2014; 27, 114-119. 
Research, Society and Development, v. 10, n. 1, e19510111378, 2020

(CC BY 4.0) | ISSN 2525-3409 | DOI: http://dx.doi.org/10.33448/rsd-v10i1.11378

Arnaldo, L., P., \& Celmo, C. P (2014). Semiologia Médica. Guanabara Koogan, (7a ed.).

Bader, H. S., et al. (2018).Clinical patterns of postcholecystectomy syndrome. Ann Hepatobiliary Pancreat Surg, 22, 52-57.

Caio, G. M., et al. (2017). Coledocolitíase: da suspeita ao diagnóstico. Arq Med Hosp Fac Cienc Med Santa Casa São Paulo, 62, 35-41.

Craig, N. (2020). Serotonin-norepinephrine reuptake inhibitors (SNRIs): Pharmacology, administration, and side effects. In: Lee S, UpToDate.

Drossman, D. A., et al. (2006). Rome III: the functional gastrointestinal disorders. VA: Degnon Associates, 49, 885-893.

Finlay, A. M. (2020). Overview of colon polyps. In: Lee S, UpToDate.

Hongbeom, K., et al. (2018). Postcholecystectomy syndrome: symptom clusters after laparoscopic cholecystectomy. Ann Surg Treat, 95:135-140.

Jaunoo, S. S., et al. (2010). Postcholecystectomy syndrome (PCS). Int J Surg, 8:15-17.

Jennifer, I., et al. (2019). A systematic review of the aetiology and management of post cholecystectomy syndrome. The Surgeon, 17:33-42.

José, S. S., et al. (2008). Colecistectomia: aspectos técnicos e indicações para o tratamento da litíase biliar e das neoplasias. Medicina- USP (Ribeirão Preto), 41:449-464.

Júlio, C. U. C., et al. (2009). Prevalência e fisiopatologia da litíase biliar em pacientes submetidos a transplante de órgãos. Arq Bra Cir Dig, 22:120-123.

Kok-Ann, G., et al. (2017). Irritable bowel syndrome in Asia: Pathogenesis, natural history, epidemiology, and management. J Gastroenterol Hepat, 33:99110.

Madacsy, L., et al. (2015). Postcholecystectomy syndrome: from pathophysiology to differential diagnosis - a critical review. Pancreat Disord Ther, 5:162.

Maria, C. A. M., et al. (2009). Colecistite aguda: diagnóstico e tratamento. Rev Hosp Univer Pedro Ernesto, 8: 52-60.

Robert, M. (2018). Approach to minimal bright red bleeding per rectum. In: Lee S, UpToDate.

Turumin, J. L., et al. (2013). The role of the gallbladder in humans. Rev Gastroenterol Mex, 78:177-187.

William, D. C., et al. (2015). Irritable Bowel Syndrome: A Clinical Review. Cli Rev Edu, 313:949-958.

Zackria, R., \& Waheed, A. (2020). Postcholecystectomy Syndrome.In: StatPearls. Treasure Island (FL): StatPearls Publishing. 